\title{
Cycloaminals of trichloroacetaldehyde: synthesis and their use as carbene-precursors
}

\author{
Christiane Petzold ${ }^{\mathrm{a}}$, Rainer Beckert*a, Wolfgang Günther, and Helmar Görls ${ }^{\mathrm{b}}$ \\ ${ }^{a}$ Institute of Organic and Macromolecular Chemistry, Friedrich-Schiller-University, \\ Humboldtstr. 10, D-07743 Jena, Germany, ${ }^{b}$ Institute of Inorganic and Analytical Chemistry, \\ Friedrich-Schiller-University, August-Bebel-Str. 2, D-07743 Jena, Germany \\ E-mail: c6bera@uni-jena.de
}

Dedicated to Professor Ernst Anders on the occasion of his $65^{\text {th }}$ birthday

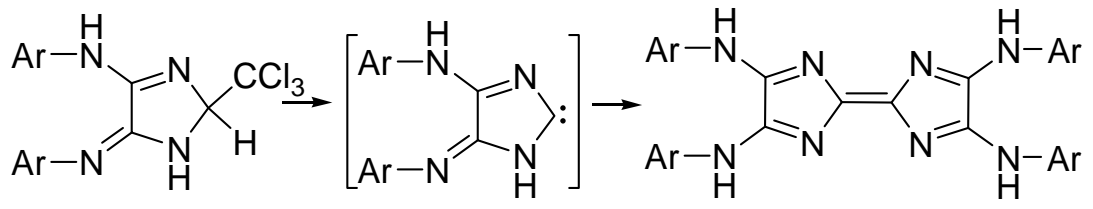

\begin{abstract}
Trichloroacetaldehyde was successfully used for the cyclisation of bis-amidines of oxalic acid $\mathbf{1}$ to afford cycloaminals in good yields. Although prototropism is a characteristic feature of the amidines the cyclisation reaction can be realized in a regioselective manner to give three types of cycloaminals 6, 7 and 8. Starting from cycloaminals 8 carbenes can be generated which immediately dimerize to the corresponding 2,3,6,7-tetrakis(arylamino)-1,4,5,8-tetraazafulvalenes 5.
\end{abstract}

Keywords: Carbenes, cycloaminals, oxalic amidines, tetraazafulvalenes

\section{Introduction}

Disubstituted amidines of oxalic acid of type $\mathbf{1}$ are easily accessible by aminolysis reaction of oxalic acid bis-imidoylchlorides. ${ }^{1}$ Due to their four nucleophilic centres they are of interest as starting materials for several heterocycles. However, the amidines $\mathbf{1}$ undergo facile E/Zinterconversion and prototropic processes called "tautomeric rotation" 2 , therefore cyclisation reactions with electrophiles often tend to the formation of regioisomeric compounds. In contrast to the s-trans conformation present in the solid state of $1\left(\mathrm{Ar}=4-\mathrm{MeC}_{6} \mathrm{H}_{4}\right)$ in solution these derivatives exist in several prototropic isomers depending on the solvent, e.g. 1' ${ }^{1}$. Thus, trialkyl 
orthoformates react with $\mathbf{1}$ including all four nitrogen atoms to form mixtures of diastereomeric tetrahydroimidazol[4,5-d]imidazoles $\mathbf{2}^{1}$. Unfortunately, these aminal esters are unsuitable for the use as carbene precursors because the elimination of alcohol occurs only at higher temperatures under the formation of tarry-like materials. Previously, we reported a simple reaction of $\mathbf{1}$ with the Vilsmeier reagent which resulted in the formation of tetraazafulvalenes $5{ }^{1}$. As keyintermediate in a complex reaction, most-likely the cyclisation product 3 was formed in a regioselective manner. The instable orthoamide rapidly undergoes $\alpha$-elimination to carbenes 4 which finally dimerize to the stable compounds $\mathbf{5}$.

Stimulated by the work of Wanzlick ${ }^{3}$ our further attempts were guided to cyclisation reactions of $\mathbf{1}$ with trichloroacetaldehyde. The resulting cyclic aminals should possess a typical substructure for $\alpha$-elimination that was applied earlier for the synthesis of numerous electronrich olefins. ${ }^{3}$ By this way in the course of a normal $\alpha$-elimination arising carbenes are meant to represent alternative precursors for tetraazafulvalenes $5^{4}$. In addition, due to their 1,4-diazadiene substructures the target molecules are of interest as efficient chelating ligands for numerous $d$ metals.

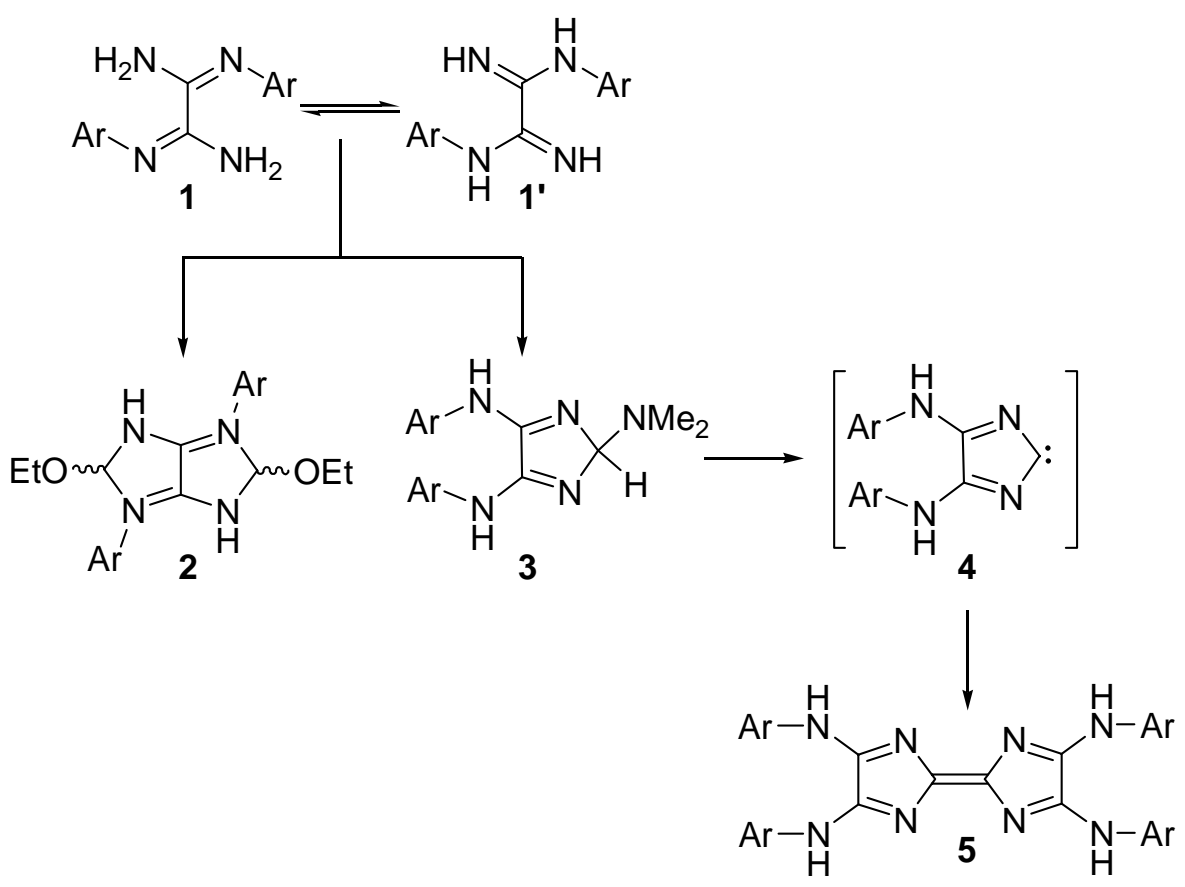

\section{Scheme 1}

\section{Results and Discussion}

Upon heating the amidine 1a for short time with trichloroacetaldehyde in glacial acetic acid a white precipitate is formed. Elemental analyses and spectroscopic data (MS, NMR) indicated a 
compound with the structure of $\mathbf{6}$. X-ray analysis of single crystals of the product allowed a final statement about the regioselectivity of this cyclisation reaction. As depicted in Scheme 2, the ring-closure took place including two different nitrogen atoms. Remarkably, the conversion of one $=\mathrm{NH}$-fragment into a carbonyl group in the manner of a hydrolysis reaction took place.

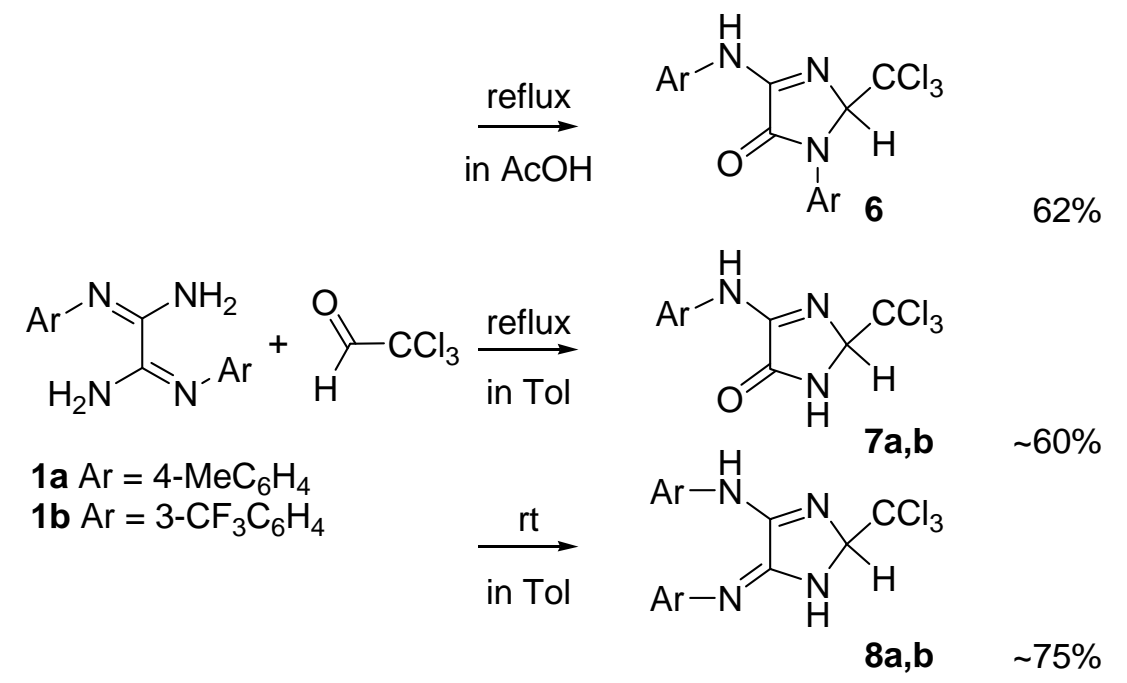

Scheme 2

The formation of product $\mathbf{6}$ can be traced back by an azomethine-like intermediate $\mathbf{A}$ (path $\boldsymbol{a}$, Scheme 3 ). The regioselectivity might be explained by reversible protonation processes at aryl amino nitrogen as well as at imino nitrogen which is then blocked for the cyclisation reaction.

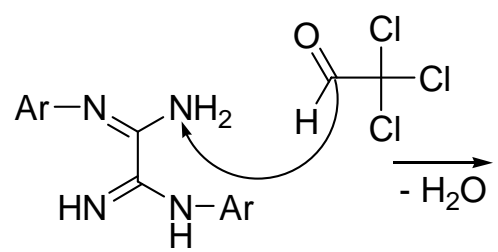

1

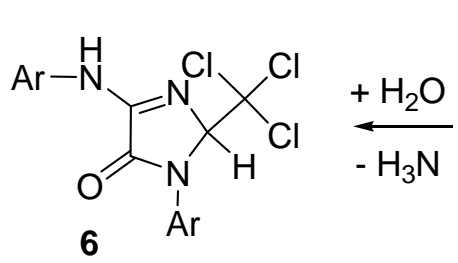

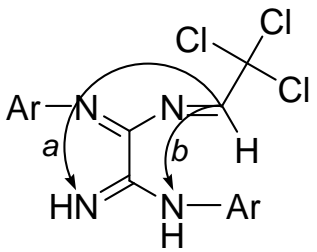

A<smiles>COCCO</smiles><smiles>N=C1C(N[Al])=NC(C(Cl)(Cl)Cl)N1[Al]</smiles><smiles>[C+]C=O</smiles><smiles>[Al]N=C1NC(C(Cl)(Cl)Cl)N=C1N[Al]</smiles>

8<smiles>C[Al-][Te](C)C=O</smiles><smiles>[3H]NC1=NC(C(Cl)(Cl)Cl)NC1=O</smiles>

\section{Scheme 3}


In further experiments toluene was used as solvent, already after short reaction times two different products were detected by TLC. Evidence for the successful cyclisation reaction gave the molar mass at $m / z=361$ for $\mathbf{7 b}$ and 395 for $\mathbf{8 a}$ as well as the characteristic signals obtained in the ${ }^{1} \mathrm{H}$-NMR spectra of 7/8. Single crystal X-ray analysis allowed an unambiguous structural assignment of these compounds, as shown in Figure 1. The structure of $\mathbf{7}$ is similar to the one of 6, despite the fact that here the ring-closure was realized by the two unsubstituted nitrogen atoms (cyclisation path $\boldsymbol{b}$, Scheme 3). Subsequent hydrolysis forms the product in which one exocyclic imino group was again converted into the carbonyl system via hydrolysis.

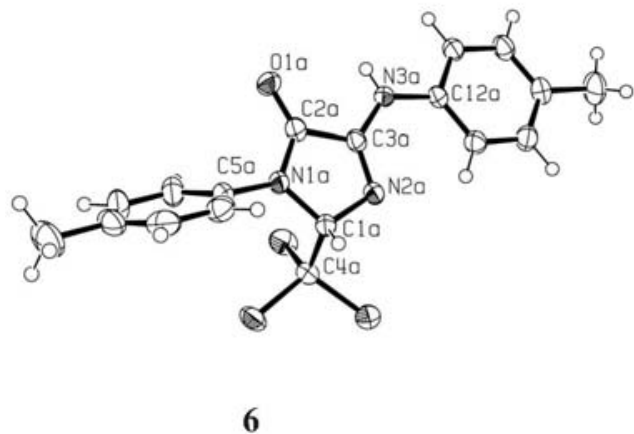

6

C1A-C4A 1.546(3)

C2A-O1A $1.217(2)$

C3A-N3A 1.348(2)

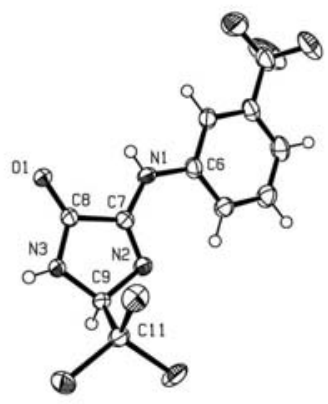

$7 \mathbf{b}$

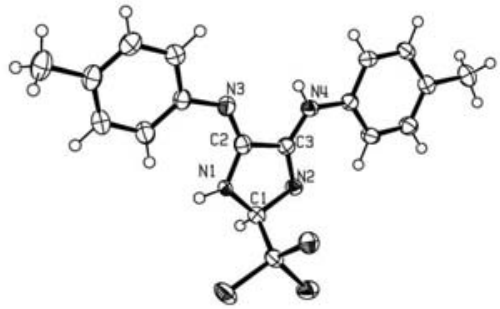

$8 \mathbf{a}$ 7b

C1-C4 1.544(3)

$\mathrm{C} 8-\mathrm{O} 11.225(3)$

C7-N1 1.348(3) 8a

C1-C4 1.540(3)

C3-N4 1.318(3)

C2-N3 1.280(3)

$\mathrm{C} 3-\mathrm{N} 21.308(3)$

C2-N1 1.352(3)

Figure 1. Structures of 6, 7b, 8a as obtained by X-ray analysis; Selected bond lengths $[\AA]$.

Compound 8 is the constitutional isomer in this cyclisation reaction possessing the structural requirements for the synthesis of tetraazafulvalenes 5. It is only formed at the cyclisation reaction at room temperature as main product, while at higher temperatures (in toluene under reflux) the hydrolysed product 7 is yielded with about $60 \%$.

Characteristic for all three types of five-membered rings (6-8) are the chemical shifts of the protons of the tertiary carbon bearing the trichloromethyl group; in HMBC-2D-NMR they show cross-peaks with the ipso-carbon of the $\mathrm{CCl}_{3}$-group and one of the oxalic acid carbons; HSQC2D-NMR of compound 8 reveals no cross-peaks with the ipso-carbon of the aryl fragment.

Furthermore, the shifts of the tertiary carbon itself and the carbonyl carbon or the imino carbon $(\mathrm{C}=\mathrm{NAr})$ are characteristic as listed below in Table 1. 
Table 1. Characteristic chemical shifts $\left({ }^{1} \mathrm{H}-/{ }^{13} \mathrm{C}-\mathrm{NMR}\right.$ in DMSO-D $\left.[\mathrm{ppm}]\right)$ of the cycloaminals of types 6,7 and 8

\begin{tabular}{cccccc}
\hline & $\mathbf{6}$ & $\mathbf{7 a}$ & $\mathbf{7 b}$ & $\mathbf{8 a}$ & $\mathbf{8 b}$ \\
\hline $\mathrm{CHCCl}_{3}$ & 6.12 & 5.89 & 6.00 & 6.69 & 6.85 \\
$\mathrm{C}_{\text {tert }} \mathrm{HCCl}_{3}$ & 87.5 & 84.7 & 84.1 & 103.8 & 104.1 \\
$\mathrm{CCl}_{3}$ & 100.8 & 101.0 & 100.1 & 98.8 & 98.1 \\
$\mathrm{C}=\mathrm{O}(C=\mathrm{NAr})$ & 161.4 & 164.3 & 163.4 & 154.1 & 154.2 \\
\hline
\end{tabular}

Further attempts were made to investigate the suitability of the cycloaminals 6-8 as precursor molecules for carbenes. Heating up of the compounds under the microscope gave the first evidence for the formation of tetraazafulvalenes 5 . The color of the melt turned deeply red at temperatures of about $100 \mathrm{~K}$ above the melting point and in addition, gas generation was visible. Thermogravimetric measurements confirmed the elimination of $\mathrm{CHCl}_{3}$ at temperatures of about $240^{\circ} \mathrm{C}$. Upon heating amounts of $100 \mathrm{mg}$ of derivatives 8a,b in a metal bath at such temperatures, the tetraazafulvalenes $5 \mathbf{a}$,b could be detected by TLC. Possibly, these heterofulvalenes have been formed via dimerization reactions of preformed but unstable carbenes. The optimization of this synthesis (milder conditions, larger scale) will be the aim of further studies.

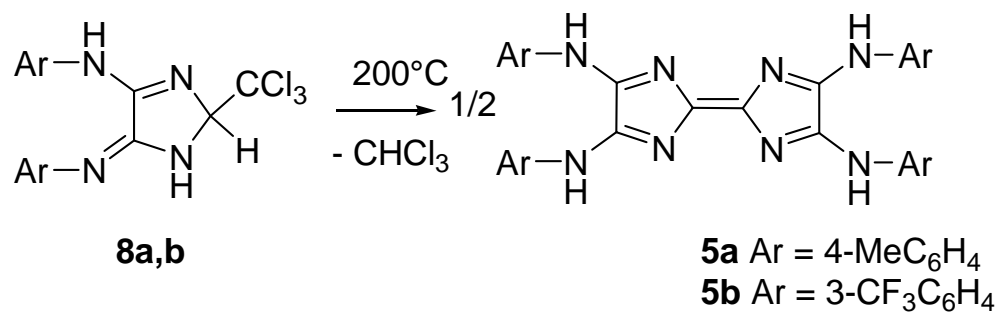

\section{Scheme 4}

\section{Experimental Section}

General Procedures. Reactions were monitored by TLC, carried out on $0.2 \mathrm{~mm}$ Merck silica gel plates $\left(60 \mathrm{~F}_{254}\right)$ using UV-light, column chromatography was carried out on Merck silica gel 60 $(0.040-0.063 \mathrm{~mm}) .{ }^{1} \mathrm{H}-$ and ${ }^{13} \mathrm{C}-\mathrm{NMR}$ spectra were obtained on a Bruker DRX 400 or AVANCE 400, Bruker AC 250 spectrometer. The remaining protons of the deuterated solvents were used as internal standard. Melting points are measured with a Galen III apparatus (Boëtius system) and are uncorrected. IR spectra were recorded on a Digital Division FTS 25 from BioRad. MS spectra were taken from measurements on a Finnigan MAT SAQ 710 mass spectrometer or TRIO 2000 from FISONS. Elemental analyses were carried out in-house with an automatic analyzer LECO CHNS 932. 
The bis-amidines of oxalic acid 1a,b and tetraazafulvalenes 5a,b were synthesized according to literature $^{1,4}$.

\section{3-(4-Tolyl)-5-(4-tolylamino)-2-trichloromethyl-2,3-dihydro-imidazol-4-one (6)}

Bis-amidine 1a $(3.7 \mathrm{mmol}, 985 \mathrm{mg})$ and freshly distilled trichloroacetaldehyde $(4.7 \mathrm{mmol}, 0.46$ $\mathrm{ml}$ ) were heated for $30 \mathrm{~min}$ under reflux in glacial acetic acid. A pale-yellow precipitate was formed and the reaction mixture was kept in the fridge overnight. The crude product was recrystallised from toluene/methanol to yield $912 \mathrm{mg}$ of a white crystalline solid (2.3 mmol, $62 \%$ ); mp $223{ }^{\circ} \mathrm{C}$; Anal. Calcd. $\mathrm{C}_{18} \mathrm{H}_{16} \mathrm{Cl}_{3} \mathrm{~N}_{3} \mathrm{O}$ : C, 54.50; H, 4.07; N, 10.59; $\mathrm{Cl}$ 26.81. Found: $\mathrm{C}$, 55.12; H, 4.14; N, 10.36; Cl 26.22; IR (ATR) 3294, 3141, 2917, 1899, 1712, $1642 \mathrm{~cm}^{-1}$; ${ }^{1} \mathrm{H}-$ NMR (400 MHz, DMSO-D $) \delta 10.00(\mathrm{~s}, 1 \mathrm{H}, \mathrm{NH}), 7.91$ (d, 2H, $J=12 \mathrm{~Hz}), 7.39$ (d, 2H, J=8 $\mathrm{Hz}), 7.29$ (d, 2H, $J=8 \mathrm{~Hz}), 7.16(\mathrm{~d}, 2 \mathrm{H}, J=12 \mathrm{~Hz}), 6.74(\mathrm{~s}, 1 \mathrm{H}), 2.37$ (s, 3H), $2.34 \mathrm{ppm}(\mathrm{s}, 3 \mathrm{H})$; ${ }^{13} \mathrm{C}-\mathrm{NMR}\left(100 \mathrm{MHz}, \mathrm{DMSO}-\mathrm{D}_{6}\right) \delta 161.4,155.8,137.5,137.1,134.2,132.6,129.9,129.6,126.2$, 119.6, 100.8, 87.5, 21.2, 20.9 ppm; MS (DEI, m/z) $395\left(\mathrm{M}^{+}, 5 \%\right), 359(5 \%), 324(2 \%), 278\left(\mathrm{M}^{+}\right.$$\left.\mathrm{CCl}_{3}, 100 \%\right), 133$ (15\%), 118 (35\%), $91(20 \%), 65$ (10\%).

\section{5-(4-tolylamino)-2-trichloromethyl-2,3-dihydro-imidazol-4-one (7a)}

The bis-amidine 1 (3.7 mmol, 1a: $985 \mathrm{mg}, \mathbf{1 b}: 1384 \mathrm{mg})$ and chloral (4.0 mmol, $0.39 \mathrm{ml})$ are heated in toluene $(30 \mathrm{ml})$ under reflux for 4 hours. The solvent was removed in vacuo, the residue was washed with $n$-heptane and recrystallised from chloroform.

Compound 7a was obtained as a white solid, $658 \mathrm{mg}(2.1 \mathrm{mmol}, 58 \%)$. mp $198{ }^{\circ} \mathrm{C}$; Anal. Calcd. $\mathrm{C}_{11} \mathrm{H}_{10} \mathrm{Cl}_{3} \mathrm{~N}_{3} \mathrm{O}$ : C, 43.09; H, 3.29; N, 13.71; Cl 34.69. Found: $\mathrm{C}$, 43.56; H, 3.60; N, 13.67; $\mathrm{Cl}$ 34.64; IR (ATR) 3377, 3164, 3089, 3059, 2901, 1738, $1647 \mathrm{~cm}^{-1} ;{ }^{1} \mathrm{H}-\mathrm{NMR}$ (400 MHz, DMSO$\left.\mathrm{D}_{6}\right) \delta 10.61\left(\mathrm{~s}, \mathrm{br}, 1 \mathrm{H}, \mathrm{NH}_{\mathrm{Tol}}\right), 9.68$ (s, 1H, $\left.\mathrm{NH}_{\text {Ring }}\right), 7.85$ (d, 2H, $\left.J=8 \mathrm{~Hz}\right), 7.12(\mathrm{~d}, 2 \mathrm{H}, J=8$ $\mathrm{Hz}), 5.89$ (s, 1H), 2.25 ppm (s, 3H); ${ }^{13} \mathrm{C}-\mathrm{NMR}\left(100 \mathrm{MHz}, \mathrm{DMSO}-\mathrm{D}_{6}\right) \delta 164.3,157.0,137.3$, 132.2, 129.5, 119.4, 101.0, 84.7, 20.9 ppm; MS (DEI, m/z) $305\left(\mathrm{M}^{+}, 1 \%\right), 271$ (1\%), 269 (2\%), $235(2 \%), 188\left(\mathrm{M}^{+}-\mathrm{CCl}_{3}, 100 \%\right), 133(90 \%), 118(30 \%), 91(25 \%), 65(10 \%)$.

5-(4-Trifluoromethylphenylamino)-2-trichloromethyl-2,3-dihydro-imidazol-4-one (7b) was obtained as a white solid, $757 \mathrm{mg}(2.1 \mathrm{mmol}, 57 \%)$. mp $170{ }^{\circ} \mathrm{C}$; Anal. Calcd. $\mathrm{C}_{11} \mathrm{H}_{7} \mathrm{Cl}_{3} \mathrm{~F}_{3} \mathrm{~N}_{3} \mathrm{O}$ : C, 36.64; H, 1.96; N, 11.65; Cl 29.50. Found: C, 36.48; H, 1.94; N, 11.59; Cl 29.86; IR (ATR) 3372, 3172, 3091, 3061, 1735, $1653 \mathrm{~cm}^{-1}$; ${ }^{1} \mathrm{H}-\mathrm{NMR}\left(250 \mathrm{MHz}, \mathrm{DMSO}_{6}\right.$ ) $\delta 10.74(\mathrm{~s}, 1 \mathrm{H})$, 10.25 (s, 1H), $8.51(\mathrm{~s}, 1 \mathrm{H}), 8.17(\mathrm{~d}, 1 \mathrm{H}, J=8 \mathrm{~Hz}), 7.56$ (t, 1H, $J=7.9 \mathrm{~Hz}), 7.37$ (d, 1H, $J=7.8$ $\mathrm{Hz}), 6.00 \mathrm{ppm}(\mathrm{s}, 1 \mathrm{H}) ;{ }^{13} \mathrm{C}-\mathrm{NMR}\left(63 \mathrm{MHz}, \mathrm{DMSO}_{6}\right) \delta 163.4,156.9,140.1,129.8,129.5$ (q, $J$ $=35 \mathrm{~Hz}), 124.1(\mathrm{q}, J=272 \mathrm{~Hz}), 122.4,119.0(\mathrm{q}, J=4.3 \mathrm{~Hz}), 115.1(\mathrm{q}, J=4.3 \mathrm{~Hz}), 100.1,84.1$ ppm; MS (DEI, m/z) $361\left(\mathrm{M}^{+}, 1 \%\right), 323$ (10\%), $289(5 \%), 261(5 \%), 242\left(\mathrm{M}^{+}-\mathrm{CCl}_{3}, 100 \%\right)$, 187 (100\%), 145 (40\%), 109 (10\%), 95 (10\%).

\section{4-Tolyl-(5-(4-tolylimino)-2-trichloromethyl-2,5-dihydro-1H-imidazol-4-yl)-amine (8a)}

The bis-amidine 1 (3.7 mmol, 1a: $985 \mathrm{mg}, \mathbf{1 b}: 1384 \mathrm{mg}$ ) and trichloroacetaldehyde (4.0 mmol, $0.39 \mathrm{ml})$ are stirred in dry toluene $(30 \mathrm{ml})$ at $\mathrm{rt}$ for several hours. The progress of the reaction was controlled by TLC (silica, toluene). After two hours (still small amount of 1 remaining) the solvent was removed in vacuo, the residue was suspended and stirred in $n$-heptane. Product 7 
which is not soluble in $n$-heptane was filtered off, whereas 8 was obtained pure from the filtrate by column chromatography (silica, toluene).

$1.1 \mathrm{~g}(2.77 \mathrm{mmol}, 75 \%)$ of a white solid were obtained; mp $158{ }^{\circ} \mathrm{C}$; Anal. Calcd. $\mathrm{C}_{18} \mathrm{H}_{17} \mathrm{Cl}_{3} \mathrm{~N}_{4}$ : C, 54.63; H, 4.33; N, 14.16; Cl 26.88. Found: C, 54.85; H, 4.47; N, 14.01; Cl 26.42; IR (ATR) 3386, 3357, 3028, 2923, 2855, 1703, $1645 \mathrm{~cm}^{-1}$; ${ }^{1} \mathrm{H}-\mathrm{NMR}\left(400 \mathrm{MHz}, \mathrm{DMSO}_{6}\right) \delta 9.89(\mathrm{~s}, 1 \mathrm{H}$, $\left.\mathrm{NH}_{\mathrm{Tol}}\right), 7.86(\mathrm{~d}, 2 \mathrm{H}, J=8 \mathrm{~Hz}), 7.22$ (s, 4H, Tolyl), 7.17 (d, 2H, J=8 Hz), 6.69 (s, 1H), 2.30 (s, 3H), 2.27 ppm (s, 3H); ${ }^{13} \mathrm{C}-\mathrm{NMR}\left(100 \mathrm{MHz}, \mathrm{DMSO}_{6}\right) \delta$ 154.1, 149.0, 141.4, 136.5, 134.8, 132.3, 129.5, 129.1, 123.1, 119.2, 103.8, 98.8, 20.6, 20.4 ppm; MS (DEI, m/z) $395\left(\mathrm{M}^{+}\right.$, 1\%), $390(1 \%), 326(1 \%), 278\left(\mathrm{M}^{+}-\mathrm{CCl}_{3}, 100 \%\right), 227(20 \%), 133(40 \%), 118(50 \%), 91(85 \%)$, $77(20 \%), 65(20 \%)$.

\section{3-Trifluoromethylphenyl-(5-(3-trifluoromethylphenylimino)-2-trichloromethyl-2,5-}

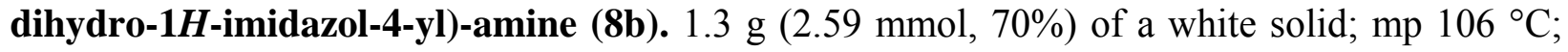
Anal. Calcd. $\mathrm{C}_{18} \mathrm{H}_{11} \mathrm{Cl}_{3} \mathrm{~F}_{6} \mathrm{~N}_{4}$ : C, 42.92; H, 2.20; N, 10.87; Cl 21.12. Found: C, 42.35; H, 2.02; N, 10.87; Cl 20.90; IR (ATR) 3377, 3090, 2956, 2925, 2854, 1709, 1655, $1616 \mathrm{~cm}^{-1} ;{ }^{1} \mathrm{H}-\mathrm{NMR}(250$ MHz, DMSO-D 6$) \delta 10.60(\mathrm{~s}, 1 \mathrm{H}), 8.49(\mathrm{~s}, 1 \mathrm{H}), 8.24(\mathrm{~d}, 1 \mathrm{H}, J=7.5 \mathrm{~Hz}), 7.71-7.57(\mathrm{~m}, 5 \mathrm{H}), 7.45$ $(\mathrm{d}, 1 \mathrm{H}, J=7.5 \mathrm{~Hz}), 6.85 \mathrm{ppm}(\mathrm{s}, 1 \mathrm{H}) ;{ }^{13} \mathrm{C}-\mathrm{NMR}\left(63 \mathrm{MHz}, \mathrm{DMSO}_{6}\right) \delta 154.2,150.9,144.8$, 139.7, 130.5, 130.1, 129.9 (q, $J=3.1 \mathrm{~Hz}), 129.6$ (q, $J=31 \mathrm{~Hz}), 127.1,126.1$ (q, $J=8.2 \mathrm{~Hz})$, 122.9, 122.1 (q, $J=3.1 \mathrm{~Hz}), 121.8(\mathrm{q}, J=8.2 \mathrm{~Hz}), 119.8(\mathrm{q}, J=8.2 \mathrm{~Hz}), 119.3(\mathrm{q}, J=3.8 \mathrm{~Hz})$, 115.6 (q, $J=4.4 \mathrm{~Hz}), 104.1,98.1$ ppm; MS (DEI, m/z) $505\left(\mathrm{M}^{+}, 1 \%\right), 467(1 \%), 386\left(\mathrm{M}^{+}-\mathrm{CCl}_{3}\right.$, 80\%), 317 (5\%), 281 (20\%), 253 (10\%), 219 (10\%), 187 (60\%), 172 (100\%), 145 (70\%).

\section{Generation of carbenes and their dimerization to tetraazafulvalene 5 a}

In a Schlenk-vessel derivative $8 \mathbf{a}(0.25 \mathrm{mmol})$ was heated at $200^{\circ} \mathrm{C}$ (metal bath) for $30 \mathrm{~min}$ under stirring. The reaction was stopped, when the colour of the melt turned to red-brown. Then the mixture was cooled down to rt and a small amount of methanol was added. The crude product was filtered off and purified according to the procedure reported in the literature ${ }^{4}$. The comparison of the product with authentic material by TLC gave identity. Tetraazafulvalene 5a was obtained as a red-brown solid ( $17 \mathrm{mg}, 0.03 \mathrm{mmol}, 25 \%) ; \mathrm{mp} 281^{\circ} \mathrm{C}$ (lit. $280-282^{\circ} \mathrm{C}$ ).

\section{Crystal Structure Determination}

The intensity data for the compounds were collected on a Nonius KappaCCD diffractometer, using graphite-monochromated $\mathrm{Mo}-\mathrm{K}_{\alpha}$ radiation. Data were corrected for Lorentz and polarization effects, but not for absorption ${ }^{5,6}$.

The structures were solved by direct methods (SHELXS ${ }^{7}$ ) and refined by full-matrix least squares techniques against $\mathrm{Fo}^{2}$ (SHELXL-97 ${ }^{8}$ ). For the amine-group of the compounds the hydrogen atoms were located by difference Fourier synthesis and refined isotropically. The other hydrogen atoms of the structures were included at calculated positions with fixed thermal parameters. All non-hydrogen atoms were refined anisotropically ${ }^{8}$. XP (SIEMENS Analytical Xray Instruments, Inc.) was used for structure representations.

Crystal Data for $6{ }^{9}: \mathrm{C}_{18} \mathrm{H}_{16} \mathrm{Cl}_{3} \mathrm{~N}_{3} \mathrm{O}, \mathrm{Mr}=396.69$ gmol $^{-1}$, colourless prism, size $0.03 \times 0.03 \times$ $0.02 \mathrm{~mm}^{3}$, triclinic, space group $\mathrm{P} \overline{1}, \mathrm{a}=9.5138(3), \mathrm{b}=14.4024(4), \mathrm{c}=14.9137(4) \AA, \alpha=$ 
104.860(2), $\beta=100.777(2), \gamma=102.141(2)^{\circ}, \mathrm{V}=1867.16(9) \AA^{3}, \mathrm{~T}=-90{ }^{\circ} \mathrm{C}, \mathrm{Z}=4, \rho_{\text {calcd. }}=1.411$ $\mathrm{gcm}^{-3}, \mu\left(\mathrm{Mo}-\mathrm{K}_{\alpha}\right)=5.02 \mathrm{~cm}^{-1}, \mathrm{~F}(000)=816,14057$ reflections in $\mathrm{h}(-11 / 12), \mathrm{k}(-18 / 18), 1(-18 / 19)$, measured in the range $2.36^{\circ} \leq \Theta \leq 27.43^{\circ}$, completeness $\Theta_{\max }=99.6 \%, 8499$ independent reflections, $R_{\text {int }}=0.024,6627$ reflections with $F_{o}>4 \sigma\left(F_{o}\right), 460$ parameters, 0 restraints, $R 1_{\text {obs }}=$ $0.042, \mathrm{wR}^{2}{ }_{\mathrm{obs}}=0.105, \mathrm{R} 1_{\text {all }}=0.062, \mathrm{wR}_{\text {all }}^{2}=0.1172, \mathrm{GOOF}=0.996$, largest difference peak and hole: $0.360 /-0.439$ e $\AA^{-3}$.

Crystal Data for $7 \mathbf{b}^{9}: \mathrm{C}_{11} \mathrm{H}_{7} \mathrm{Cl}_{3} \mathrm{~F}_{3} \mathrm{~N}_{3} \mathrm{O}, \mathrm{Mr}=360.55$ gmol $^{-1}$, colourless prism, size $0.06 \mathrm{x}$ $0.05 \times 0.05 \mathrm{~mm}^{3}$, monoclinic, space group $\mathrm{P} 2_{1} / \mathrm{n}, \mathrm{a}=8.8411(3), \mathrm{b}=9.9695(4), \mathrm{c}=16.2480(7) \AA$, $\beta=101.415(2)^{\circ}, \mathrm{V}=1403.79(10) \AA^{3}, \mathrm{~T}=-90{ }^{\circ} \mathrm{C}, \mathrm{Z}=4, \rho_{\text {calcd. }}=1.706 \mathrm{gcm}^{-3}, \mu\left(\mathrm{Mo}-\mathrm{K}_{\alpha}\right)=6.87$ $\mathrm{cm}^{-1}, \mathrm{~F}(000)=720,9725$ reflections in $\mathrm{h}(-11 / 11), \mathrm{k}(-12 / 12), 1(-21 / 21)$, measured in the range $2.44^{\circ} \leq \Theta \leq 27.48^{\circ}$, completeness $\Theta_{\max }=99.8 \%, 3210$ independent reflections, $R_{\text {int }}=0.046$, 2226 reflections with $\mathrm{F}_{\mathrm{o}}>4 \sigma\left(\mathrm{F}_{\mathrm{o}}\right), 198$ parameters, 0 restraints, $\mathrm{R}_{\mathrm{obs}}=0.042, \mathrm{wR}^{2}{ }_{\mathrm{obs}}=0.095$, $\mathrm{R} 1_{\text {all }}=0.073, \mathrm{wR}_{\text {all }}^{2}=0.109, \mathrm{GOOF}=1.024$, largest difference peak and hole: $0.342 /-0.434 \mathrm{e}$ $\AA^{-3}$.

Crystal Data for 8a ${ }^{9}: \mathrm{C}_{18} \mathrm{H}_{17} \mathrm{Cl}_{3} \mathrm{~N}_{4}, \mathrm{Mr}=395.71$ gmol $^{-1}$, colourless prism, size $0.06 \times 0.06 \mathrm{x}$ $0.05 \mathrm{~mm}^{3}$, monoclinic, space group $\mathrm{P} 2{ }_{1} / \mathrm{c}, \mathrm{a}=18.5831(8), \mathrm{b}=11.4402(4), \mathrm{c}=8.5891(2) \AA, \beta=$ 94.506(2) ${ }^{\circ}, \mathrm{V}=1820.35(11) \AA^{3}, \mathrm{~T}=-90^{\circ} \mathrm{C}, \mathrm{Z}=4, \rho_{\text {calcd. }}=1.444 \mathrm{gcm}^{-3}, \mu\left(\mathrm{Mo}-\mathrm{K}_{\alpha}\right)=5.12 \mathrm{~cm}^{-1}$, $\mathrm{F}(000)=816,11921$ reflections in $\mathrm{h}(-24 / 21), \mathrm{k}(-12 / 14), 1(-11 / 10)$, measured in the range $2.83^{\circ} \leq$ $\Theta \leq 27.47^{\circ}$, completeness $\Theta_{\max }=98.1 \%, 4099$ independent reflections, $\mathrm{R}_{\mathrm{int}}=0.029,3251$ reflections with $\mathrm{F}_{\mathrm{o}}>4 \sigma\left(\mathrm{F}_{\mathrm{o}}\right), 231$ parameters, 0 restraints, $\mathrm{R} 1_{\text {obs }}=0.042$, $\mathrm{wR}_{\text {obs }}^{2}=0.114, \mathrm{R} 1_{\text {all }}=$ $0.057, \mathrm{wR}_{\text {all }}^{2}=0.124, \mathrm{GOOF}=1.044$, largest difference peak and hole: $0.545 /-0.389 \mathrm{e} \AA^{-3}$.

\section{Acknowledgements}

We thank Deutsche Forschungsgemeinschaft (DFG, SFB 436) for financial support.

\section{References}

1. Müller, D.; Beckert, R.; Görls, H. Synthesis 2001, 601.

2. Jackman, L. M.; Jen, T. J. Am. Chem. Soc. 1975, 97, 2811.

3. (a) Wanzlick, H.; Schikora, E. Angew. Chem. 1960, 72, 494. (b) Wanzlick, H.; Kleiner, H. Angew. Chem. 1961, 73, 493. (c) Wanzlick, H.; Schikora, E. Chem. Ber. 1961, 94, 2389.

4. Käpplinger, C.; Beckert, R.; Imhof, W. J. Prakt. Chem. 1998, 340, 323.

5. COLLECT, Data Collection Software; Nonius B. V.:Netherlands, 1998.

6. Z. Otwinowski, Z.; Minor, W. Processing of X-Ray Diffraction Data Collected in Oscillation Mode, In Methods in Enzymology, Vol. 276, Macromolecular Crystallography, Part A, Carter, C. W.; Sweet, R. M., Eds., pp 307-326, Academic Press: San Diego 1997.

7. Sheldrick, G. M. Acta Crystallogr. Sect. A 1990, 46, 467. 
8. Sheldrick, G. M. SHELXL-97, University of Göttingen, Germany, 1993.

9. Further details of the crystal structure investigations are available on requests from the director of the Cambridge Crystallographic Data Centre, 12 Union Road, GB-Cambridge CB2 1 EZ, on quoting the depository number CCSD-615098 (6), CCSD-615099 (7b), and CCSD-615100 (8a), the names of the authors, and the journal citation. 